\title{
FLESH ESTIMATION OF SOME SIS FISH
}

\author{
Sabina Sultana \\ Fisheries Research Laboratory, Department of Zoology, University of Rajshahi, Rajshahi 6205 \\ e-mail: seager18@yahoo.com
}

\begin{abstract}
Small Indigenous Species (SIS) of fishes of 18 species under ten families and five orders were selected for the experiment. The percentage and ratio of edible portions compared to their wastes (\%) were determined. The percentage by weight after dressing and washing was found for Corica soborna

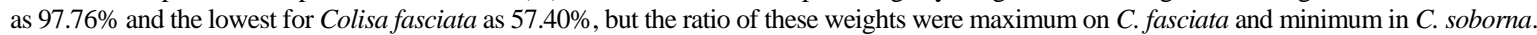

Key words: SIS, flesh

সারাংশ: পর্যবেক্ষণের জন্য পাঁচটি বর্গ এবং দশটি গোত্রের অন্তর্ভূক্ত ১৮ থ্রজাতির মাছ বাছাই করে নেয়া হয়েছিল। মাছগুলির খাদ্য উপযোগী অংশ এবং অব্যবহার্য অংশের শতকরা হার ও অনুপাত নির্ধারণ করা হয়। মাছগুলি ধোয়া এবং পরিষ্ষারের পর সর্বোচ্চ খাওয়ার উপযোগী অংশ পাওয়া গেছে Corica soborna তে যা ৯৭.৭৬\% এবং সর্বনিয্ন পাওয়া গেছে Colisa fasciata তে যা ৫৭.৪০\%, তবে এই দুই ওজনের অনুপাত সর্ব্রেচ্চ C. fasciata তে ও সর্বনিয্ন C. soborna-য়।

\section{Introduction}

Fish plays an important role in the diet of the peoples of Bangladesh. Fish constitutes the main and often irreplaceable animal source of food in rural households. In terms of weight of food consumed, fish ranks third after rice and vegetables. Regional studies have confirmed the importance of fish in the Bangladeshi diet (Hels et al. 2002). Small fishes are generally eaten with bones, whereas in large fish most or all bones are discarded as plate waste. So, small fishes are an excellent source of calcium. It have been reported that the bioavailability of calcium from whole small fish is as high as that from milk. In humans, the fractional calcium absorption is found to be $24 \pm 6 \%$ from small fish and $22 \pm 6 \%$ from milk (Larsen et al. 2000). The small indigenous species (SIS) of fishes are available in the freshwaters and can easily be grown in the neglected fallow water areas and margins of agricultural lands, roads and houses, where the large fishes cannot survive. The SIS fishes can capture using simple gears, and even children can capture these fishes with their hands from such water bodies (Alikunhi et al., 1972; Hossain and Afroze, 1991; Hossain et al., 1994; Felts et al., 1996).

The lower income groups especially of the rural areas depend on the SIS fish, and a great percentage of them used to catch the fish rather than to purchase it. As the SIS fish are cheaper than the larger fishes the section of people even can afford to buy these fish for the consumption of the whole family. The higher income group depends on market supply of big and more expensive fish species which are regarded as the icon of higher prestige (ISPAN, 1993).

Works have been done on flesh contents of different fish species by Mookherjee and Basu (1946), Hossain et al. (1999) and Hossain and Afroze (1991). Hossain et al. (1999) reported that percentage of edible flesh is higher in small sized fishes compared to large sized fishes. The present attempt was made to find out the percentage of edible portion after dressing and washing of 18 species of small fishes in terms of percentage and ratio compared to the wastes.

\section{Materials and Methods}

Sample and data collection: Samples of selected SIS fishes were collected weekly from July 2005 to September 2007, from the local fish landing centers of Rajshahi city. Usually the fishes were collected from the catch of open water system.

The samples collected were taken to the laboratory at fresh condition. To determine the edible portion and wastage after each part of dressing presently collected fishes were used. These fishes were collected early in the morning and brought to the laboratory in containers with ice flexes. In this study total 18 SIS fishes were used.

Measurements: Measurements of fishes were taken where there was no damage. Total length (TL), Standard length (SL) were measured with the help of a Millimeter scale. The weight of fresh fish was taken with the help of an electronic balance. The measurements recorded as the following:

Total length (TL) : The length from the tip of the snout up to the end of the caudal fin of the sample fish.

Standard length (SL) : The length from the tip of the snout to the base of the caudal fin of the fishes.

Total weight (TW) : Total body weight of the sample fishes.

The data of TL and TW are presented in table 1.

Processing of the fishes: After recording the measurements the fishes were washed with clean water and the excess water was soaked with kitchen tissue. Firstly, the whole body weight of the samples was recorded. Then abdomen the fishes were cut off to remove the viscera, and the scales were scrapped off, gills of some fish species were removed and weight of the fish was recorded. Then the viscera was removed and the fish was weighed again. Weight of all the wastes (viscera, fins, scales and gills) were taken. The percentage of the fish after dressing were calculated, and the ratios of the edible wastes were determined. 


\section{Results and Discussion}

In Table 1, the range and mean \pm SE total length (TL) and total weight (TW) are presented for each of the studied 18 species. Because of too small weight of individual fishes, $50-250 \mathrm{~g}$ (related to the size) of samples of each species were taken (group weight).

Table 1 Total length, total weight and weight after dressing of 18 SIS fishes

\begin{tabular}{|c|c|c|c|c|c|c|c|c|c|c|c|}
\hline \multirow[b]{2}{*}{$\begin{array}{l}\text { Sl. } \\
\text { No. }\end{array}$} & \multirow{2}{*}{$\begin{array}{l}\text { Total weight } \\
\text { of group (g) }\end{array}$} & \multirow[b]{2}{*}{ Species } & \multicolumn{3}{|c|}{ Range of TL (mm) } & \multicolumn{3}{|c|}{ Range of TW (g) } & \multicolumn{3}{|c|}{ Range of ADW (g) } \\
\hline & & & Min & $\operatorname{Max}$ & $\begin{array}{l}\text { Mean } \\
+\mathrm{SE} \\
\end{array}$ & Min & Max & $\begin{array}{l}\text { Mean } \\
+\mathrm{SE}\end{array}$ & Min & Max & $\begin{array}{c}\text { Mean } \\
+ \text { SE }\end{array}$ \\
\hline \multicolumn{12}{|c|}{$\begin{array}{l}\text { 1. Order- Perciformes, } \\
\text { 1. Family- Centropomidae }\end{array}$} \\
\hline 1 & 100 & Chanda пата & 18 & 82 & $\begin{array}{c}23.8 \\
\pm 1.72\end{array}$ & 0.2 & 6 & $\begin{array}{l}0.435 \\
\pm 0.07\end{array}$ & 64.9 & 73 & $\begin{array}{l}68.75 \\
\pm 0.94\end{array}$ \\
\hline 2 & 50 & C. ranga & 19 & 50 & $\begin{array}{l}23.6 \\
\pm 1.1\end{array}$ & 0.3 & 2.9 & $\begin{array}{l}0.835 \\
\pm 0.15\end{array}$ & 35.1 & 39.5 & $\begin{array}{l}37.97 \\
\pm 3.65\end{array}$ \\
\hline 3 & 100 & C. baculis & 19 & 62 & $\begin{array}{l}21.21 \\
\pm 0.57\end{array}$ & 0.21 & 3.9 & $\begin{array}{l}0.548 \\
\pm 0.08\end{array}$ & $\begin{array}{c}64.81 \\
\pm 81 \\
\end{array}$ & 73.5 & $\begin{array}{c}70.026 \\
\pm 0.62\end{array}$ \\
\hline \multicolumn{12}{|c|}{ 2. Family- Gobiidae } \\
\hline 4 & 100 & Glossogobius giuris & 26 & 116 & $\begin{array}{r}38.2 \\
\pm 3.85 \\
\end{array}$ & 0.3 & 25.5 & $\begin{array}{l}0.865 \\
\pm 0.26 \\
\end{array}$ & 79.5 & 85.8 & $\begin{array}{c}82.8 \\
\pm 0.73 \\
\end{array}$ \\
\hline \multicolumn{12}{|c|}{ 3. Family- Anabantidae } \\
\hline 5 & 100 & Colisa fasciata & 29 & 93 & $\begin{array}{c}55.5 \\
\pm 4.76\end{array}$ & 0.7 & 14.1 & $\begin{array}{l}4.15 \\
\pm 0.9\end{array}$ & 38.8 & 76 & $\begin{array}{c}57.4 \\
\pm 3.65\end{array}$ \\
\hline
\end{tabular}

\section{Order- Cypriniformes}

\section{Family- Cyprinidae}

\begin{tabular}{|c|c|c|c|c|c|c|c|c|c|c|c|}
\hline 6 & 50 & $\begin{array}{c}\text { Amblyoharyngodon } \\
\text { mola }\end{array}$ & 32 & 50 & $\begin{array}{c}40.6 \\
\pm 1.49\end{array}$ & 0.8 & 2.7 & $\begin{array}{c}1.35 \\
\pm 0.13\end{array}$ & 35.5 & 41.1 & $\begin{array}{c}38.84 \\
\pm 0.49\end{array}$ \\
\hline 7 & 100 & Puntius ticto & 29 & 62 & $\begin{array}{c}48.7 \\
\pm 2.78\end{array}$ & 2.2 & 7.1 & $\begin{array}{c}3.79 \\
\pm 0.25\end{array}$ & 64.9 & 70.5 & $\begin{array}{c}67.92 \\
\pm 0.56\end{array}$ \\
\hline 8 & 100 & Puntius stigma & 39 & 89 & $\begin{array}{c}43 \\
\pm 1.1\end{array}$ & 1.1 & 11.2 & $\begin{array}{c}1.365 \\
\pm 0.06\end{array}$ & 75 & 81.2 & $\begin{array}{c}77.711 \\
\pm 0.63\end{array}$ \\
\hline 9 & 100 & Aspidoparia jaya & 79 & 130 & $\begin{array}{c}87.6 \\
\pm 1.74\end{array}$ & 7.1 & 15 & $\begin{array}{c}9.35 \\
\pm 0.52\end{array}$ & 71.6 & 81.8 & $\begin{array}{c}76.76 \\
\pm 1.17\end{array}$ \\
\hline 10 & 100 & Oxygaster bacaila & 23 & 79.11 & $\begin{array}{c}32.22 \\
\pm 1.51\end{array}$ & 0.2 & 3.8 & $\begin{array}{c}0.543 \\
\pm 0.07\end{array}$ & 82.4 & 90.7 & $\begin{array}{c}86.891 \\
\pm 0.91\end{array}$ \\
\hline 11 & 100 & Cirrhina reba & 56 & 183 & $\begin{array}{c}73.11 \\
\pm 2.94\end{array}$ & 2.9 & 49.2 & $\begin{array}{c}4.25 \\
\pm 0.27\end{array}$ & 76.2 & 81.7 & $\begin{array}{c}78.721 \\
\pm 0.61\end{array}$ \\
\hline
\end{tabular}

\section{Family- Schilbeidae}

\begin{tabular}{|c|c|c|c|c|c|c|c|c|c|c|c|}
\hline 12 & 50 & Clupisoma atherinoides & 46 & 73 & $\begin{array}{c}52.8 \\
\pm 1.58 \\
\end{array}$ & 0.9 & 2.4 & $\begin{array}{l}1.47 \\
\pm 0.1 \\
\end{array}$ & 33.2 & 41.3 & $\begin{array}{c}37.55 \\
\pm 0.8 \\
\end{array}$ \\
\hline \multicolumn{12}{|c|}{ 6. Family- Cobitidae } \\
\hline 13 & 100 & Lepidocephalus guntea & 48 & 91 & $\begin{array}{c}51.0 \\
\pm 0.82\end{array}$ & 1.91 & 8.1 & $\begin{array}{l}2.333 \\
\pm 0.12\end{array}$ & 74.51 & 79.9 & $\begin{array}{l}76.83 \\
\pm 0.56\end{array}$ \\
\hline \multicolumn{12}{|c|}{ 7. Family- Bagridae } \\
\hline 14 & 150 & Mystus vittatus & 55 & 114 & $\begin{array}{c}72.21 \\
\pm 4.1\end{array}$ & 2.5 & 11 & $\begin{array}{c}4.15 \\
\pm 0.39\end{array}$ & 84.6 & 115.2 & $\begin{array}{c}104.15 \\
\pm 3.01\end{array}$ \\
\hline
\end{tabular}

\section{Order- Mastacembeliformes}

8. Family- Mastacembelidae

\begin{tabular}{|l|c|c|c|c|c|c|c|c|c|c|c|c|}
\hline 15 & 100 & $\begin{array}{c}\text { Mastacembelus } \\
\text { pancalus }\end{array}$ & 64 & 143 & $\begin{array}{c}66.9 \\
\pm 0.82\end{array}$ & 1.3 & 22.11 & $\begin{array}{c}1.522 \\
\pm 0.04\end{array}$ & 76 & 82.5 & $\begin{array}{c}79.763 \\
\pm 0.77\end{array}$ \\
$\begin{array}{l}\text { 4. Order- Clupeiformes } \\
\text { 9. Family- Clupeidae }\end{array}$ \\
\hline 16 & 100 & Gudusia chapra & 33 & 126 & $\begin{array}{c}39.1 \\
\pm 1.59\end{array}$ & 1 & 13.8 & $\begin{array}{c}1.33 \\
\pm 0.1\end{array}$ & 85 & 89 & $\begin{array}{c}86.92 \\
\pm 0.42\end{array}$ \\
\hline 17 & 50 & Corica soborna & 11 & 27 & $\begin{array}{c}18.51 \\
\pm 1.35\end{array}$ & 0.30 & 1.69 & $\begin{array}{c}1.01 \\
\pm 0.10\end{array}$ & 47.91 & 49.76 & $\begin{array}{c}48.88 \\
\pm 0.59\end{array}$ \\
\hline
\end{tabular}


Among the Chanda species, the average total lengths of the three species were similar; but after dressing the weight of edible part of $C$. ranga was found to be minimum. The ratio between edible and waste portions of C. ranga was 1:0.31, which were 1:0.45 and 1:0.42 in case of $C$. nama and C. baculis (Table 2 and Fig.1).
A. jaya having the maximum mean TL (87.60 1.74 $\mathrm{mm}$ ) among the cyprinid SIS fishes; the ratio between the edible and non-edible portions was found as 1:0.43. Whereas, A. mola, the smallest member of this group of fish (mean TL $=40.60 \pm 1.49 \mathrm{~mm}$ ) have the mentioned ratio as 1:0.28 (Table 2, Fig. 1). After dressing the percentage of edible flesh portion was $76.76 \%$ for $A$. jaya and $77.68 \%$ for A. mola.

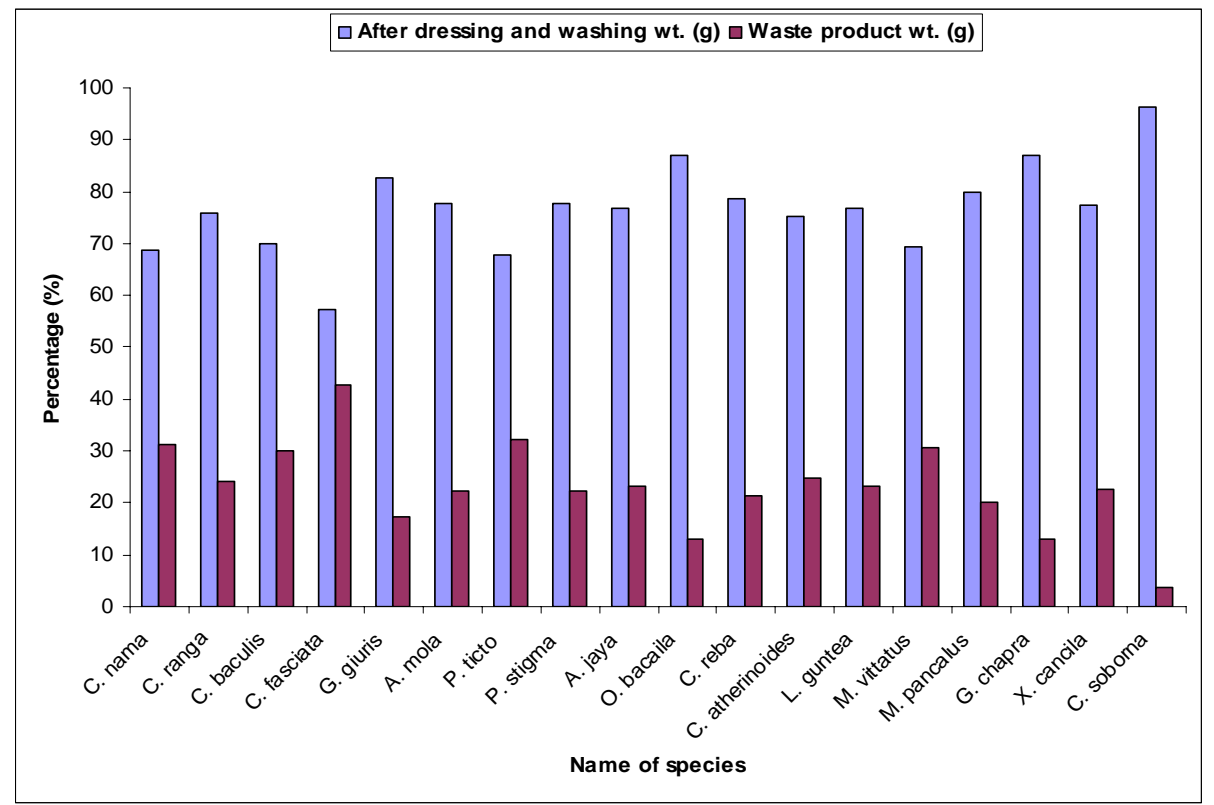

Figure 1 Percentage of after dressing weight and waste product weight.

C. soborna (mean $\mathrm{TL}=18.51 \pm 1.35 \mathrm{~mm}$ ) is a smaller fish than $G$. chapra (mean TL=39.10 $\pm 1.59 \mathrm{~mm}$ ) among the studied clupeid fishes, and the ratio between the edible and non-edible portions were 1:0.02 and 1:0.15 for these two species respectively (Table 2).

Table 2 Ratio between weight after dressing and washing weight and waste weight of the species

\begin{tabular}{|l|c|c|c|c|}
\hline \multirow{2}{*}{ Species } & \multirow{2}{*}{ Total weight taken (g) } & \multicolumn{2}{|c|}{ Per Kg weight of fish } & Ratio between weight after dressing \\
& & After dressing and washing weight (g) & Waste product (g) & anhing and waste product \\
\hline 1. C. nama & 1000 & 680.00 & 312.50 & $1: 0.45$ \\
\hline 2. C. ranga & 1000 & 759.40 & 240.60 & $1: 0.31$ \\
\hline 3. C. baculis & 1000 & 700.26 & 299.74 & $1: 0.42$ \\
\hline 4. G. giuris & 1000 & 828.00 & 171.92 & $1: 0.20$ \\
\hline 5. C. fasciata & 1000 & 574.00 & 426.00 & $1: 0.74$ \\
\hline 6. A. mola & 1000 & 776.80 & 223.20 & $1: 0.28$ \\
\hline 7. P. ticto & 1000 & 679.20 & 320.80 & $1: 0.47$ \\
\hline 8. P. stigma & 1000 & 777.11 & 222.89 & $1: 0.28$ \\
\hline 9. A. jaya & 1000 & 767.60 & 332.40 & $1: 0.43$ \\
\hline 10. . bacaila & 1000 & 868.91 & 131.09 & $1: 0.15$ \\
\hline 11. C. reba & 1000 & 787.21 & 212.79 & $1: 0.27$ \\
\hline 12. C. atherinoides & 1000 & 751.00 & 249.00 & $1: 0.33$ \\
\hline 13. L. guntea & 1000 & 768.31 & 231.69 & $1: 0.30$ \\
\hline 14. . vittatus & 1000 & 694.34 & 305.00 & $1: 0.43$ \\
\hline 15. . pancalus & 1000 & 797.63 & 202.37 & $1: 0.25$ \\
\hline 16. G. chapra & 1000 & 869.20 & 130.80 & $1: 0.15$ \\
\hline 17. C. soborna & 1000 & 977.6 & 22.4 & $1: 0.02$ \\
\hline 18. . cancila & 1000 & 774.36 & 225.64 & $1: 0.29$ \\
\hline
\end{tabular}



Economically important 18 SIS fish, which are found throughout the country used in this experiment. All these fishes are very much popular and more or less acceptable to our local people of all classes. These fishes are caught from the natural freshwater bodies. The small sized fishes like A. mola, P. ticto, C. nama, C. ranga etc., are reported to be found in a large quantity during the peak fishing season; and previous studies showed that during peak harvest large quantities of such species are thrown away while the large sized ones are supplied to the far and near markets (Parween, 1982).

Selection of the 18 fish species was based on their taste, acceptability to the consumers, availability and market price. However, the consumption pattern varies among these species. For example, the Chanda species are not so popular because of their hard bones, and comparatively less flesh content (lean fish), but because of cheap price, the poor group has a demand for these species. C. atherinoides is the least accepted species among all classes of people because of its food habit.

With the growing importance of intake of SIS fishes for vitamins and minerals, the cleaning practice of these fishes became extremely important for the retention of these nutrients. Cleaning practices depend on the fish species, size, and the organs accumulating the nutrients (Roos et al., 2002). So, the non-edible waste portion is not always are related with the size of the fish. Normally, the operculum, jaws, fins, viscera (partial/full) and the scales are included among the waste. The small sized fishes are eaten along with bones (e.g., Mola, Kachki, Darkina, etc.), whereas, because of hard and large bones, the bones of Taki, Baim, Shing, Magur which are also SIS fishes, are included as the waste. Eyes of SIS fishes are rich in vitamin A (Roos et al., 2002). The calcium obtained by eating whole mola fish is equivalent to the amount of calcium obtained in milk (Larsen et al., 2000).

For nutritional security of peoples of Bangladesh, the SIS fishes can play important role based on the following reasons:

i. a small quantity of SIS fish can be distributed evenly among the family members, which is different in case of the large size fish ;

ii. the ratio of edible and non-edible wastes are less in case of the SIS fish, so the price per unit of edible parts is comparatively less than that of the non-SIS fishes;

iii. the SIS fish can be provided to the family of lower income group daily, which will not be possible for large sized fish; iv. as the SIS fishes are eaten as a whole, and contain comparatively more nutrients and minerals, so, these fishes can protect the people from malnutrition and vitamin deficiency.

The report published by Hossain et al. (1999) provides a comparative statement of flesh content and percentage of waste obtained from a number of commercially important fish species. The authors showed that flesh weight after dressing was high in mola fish (97.76\%) compared to the carps $(62.57 \%$ for Rui, $58.62 \%$ for Catla and $57.51 \%$ for Mrigel). The present result shows the relative importance of the SIS fishes in the nutrition security of the rural poors by providing comparatively higher amount of vitamins and other nutrients.

Acknowledgements: The author is thankful to her supervisors Professor Dr. M. Altaf Hossain and Professor Dr. Selina Parween, Department of Zoology, University of Rajshahi for their invaluable guidance during the research and authorities of the Higher Education Helping Fund of the Prime Minister of Bangladesh for the fellowship.

\section{References}

Alikunhi KH, Sukumaran KK and Parmeswaran S. 1972. Studies on composite fish culture: Production by compatible combinations of Indian and Chinese carps. J. Ind. Fish. Assoc. 1: 26-27.

Felts RA, Rajts F and Akhteruzzaman M. 1996. Small Indigenous fish species culture in Bangladesh. IFADEP Sub-Project-2. Development of Inland Fisheries, 41p.

Hels O, Hassan N, Tetens H and Thilsted SH. 2002. Food consumption energy and nutrient intake and nutritional status in rural Bangladesh: Changes from 1981-82 to 1995-96. Eur. j. Clon-Nutr. 57: 586-594.

Hossain MA and Afroze S. 1991. Small Fisheries as Resource in Rural Bangladesh. Fishbyte. 9(2):15-18.

Hossain MA, Parween S and Mortuza MG. 1999. Estimation of edible contents of some fresh water fish species. Univ. j. zool. Raj. Univ. 18:169-171.

Hossain MA, Rahman MH, Parween S and Rahman MA. 1994. Fish stock assessment and utilization of seasonal ditches. J. Ecobiol. 6(1):61-66.

ISPAN. 1993. Flood control and nutritional consequences of biodiversity of fisheries irrigation support project for Asia and the near East Draft. Bangladesh Flood action plan.

Larsen T. Thilsted SH, Kongsbak K and Hansen M. 2000. Whole small fish as a rich calcium source. Br. J. Nutr. 83: 191-196.

Mookerjee HK and Basu SP. 1946. Life history of Amblypharyngodon mola (Ham) a delicate food fish of Bengal. Sci. \& Cult., Calcutta. 12(1):54-56.

Parween S. 1982. Studies on some aspects of fisheries of freshwater prawn, Macrobrachium dayanum (Hendr. 1893). of Rajshahi district. M. Phil. Thesis, Department of zoology, University of Rajshahi. 158pp.

Roos N, Leth T, Jakobsen T and Thilsted SH. 2002 High vitamin A content in some small indigenous fish species in Bangladesh: Perspectives for food based strategies to reduce vitamin A deficiency. Int. J. Food Sic. Nutr. 53: 425-437.

Manuscript received on 21 October 2012 and revised on 22 November 2012 